\title{
PRODUTOS ALTERNATIVOS NO CONTROLE DE DOENÇAS FÚNGICAS - REVISÃO BIBLIOGRÁFICA
}

\author{
Luciene Laurett ${ }^{1}$ \\ Jackson Roberto Dias Ribeiro ${ }^{2}$ \\ Edney Leandro da Vitória ${ }^{3}$
}

Resumo: As doenças fúngicas geram grandes prejuízos na agricultura, em alguns casos dependendo do grau de severidade da doença as perdas podem atingir 100\% da cultura. As perdas ocasionadas por fungos incidem tanto na redução da produção como na perda de qualidade do produto. $O$ uso de produtos alternativos é pouco utilizado, sendo limitado aos modelos de produção agroecológica e agricultura familiar. Com a tendência da população em se preocupar com a procedência dos alimentos e sua forma de produção devido ao uso incorreto e abusivo de produtos agroquímicos, os produtos alternativos podem ser utilizados assegurando a produtividade agrícola, acompanhada da conservação dos solos, água e da preservação da saúde humana.

Palavras-chave: Agricultura sustentável; Doenças fúngicas; Agroquímicos.

\footnotetext{
${ }^{1}$ Mestranda do Programa de Pós-graduação em Agricultura Tropical, Universidade Federal do Espírito Santo (UFES), Brasil. E-mail: lucienelaurett@gmail.com.

2 Mestrando do Programa de Pós-graduação em Agricultura Tropical, Universidade Federal do Espírito Santo (UFES), Brasil. E-mail: jacksonrdr@msn.com.

3 Professor do Departamento de Ciências Agrárias e Biológicas - DCAB, Universidade Federal do Espírito Santo (UFES), Brasil. E-mail: vitoria.edney@gmail.com.
} 